\title{
PSYCHE
}

\begin{tabular}{lll}
\hline Vol. 53 & March-June, 1946 & Nos. 1-2 \\
\hline
\end{tabular}

\section{PARTURITION IN PERIPATUS}

\author{
By Peter R. Morrison \\ Biological Laboratories, Harvard University, \\ Cambridge, Massachusetts
}

Despite numerous and extensive studies on the habits and life history of various of the Onychophora, ${ }^{1-5}$ with the exception of Steel ${ }^{4}$ who reported no details, there appear to have been no observations on parturition in this group. This is perhaps not surprising when one considers their retiring nature and strong negatively phototropic reactions which make difficult even the observation of the more ordinary activities such as ecdysis and feeding. Since their viviparous mode of reproduction is one of their more unusual characteristics, observations on parturition are of interest.

These peripatus were secured on Barro Colorado Island, C. Z., through the great kindness of Mr. James Zetek. They were taken in September of 1941 and these observations were made in Cambridge about a month later. During the interim they were kept in moist forest debris but were not given additional suitable food. The large female in which successful parturition was observed had an extended length of $60 \mathrm{~mm}$, had 33 pairs of legs and was uniformly colored a rich red-brown. It was Epiperipatus brasiliensis vagans Brues, ${ }^{6}$ for which the Island is the type locality. Twenty three days previously she had given birth to a single young and another was found just before these observations were made.

\footnotetext{
${ }^{1}$ Manton, S. M., Ann. Mag. Nat. Hist., (11) 1:515-528 (1938).

${ }^{2}$ Holliday, R. A., Ann. Natal Mus., 10:237-244 (1942).

${ }^{3}$ Andrews, E. A., Quart. Rev. Biol., 8:155-163 (1933).

${ }^{4}$ Steel, T., Proc. Linnean Soc. New South Wales, 21:94-104 (1896).

${ }^{5}$ Sedgwick, A., Quart. Jour. Micr. Sci., 28:431-493 (1887).

${ }^{8}$ Brues, C. T., Psyche, 32:159-165 (1925).
} 
When first noticed only $4 \mathrm{~mm}$ of the young was visible but by 15 minutes later, $16 \mathrm{~mm}$ or more than half of its length had emerged. Another 15 minutes sufficed for the young to completely free itself so that the entire process must have required little more than half an hour. During this time the female held

TABLE 1

\begin{tabular}{|c|c|c|}
\hline $8: 45$ A.M. & $\ldots \ldots$ & $4 \mathrm{~mm}$. free \\
\hline $9: 00$ & $\ldots \ldots \ldots \ldots 1$ & 16 " " \\
\hline $9: 05$ & $\ldots \ldots \ldots \ldots 2$ & 20 “ \\
\hline $9: 10$ & $\ldots 2$ & $24 " 6$ \\
\hline $9: 15$ & $\ldots \ldots \ldots \ldots$ & Completely free \\
\hline $9: 17$ & $\ldots \ldots \ldots \ldots$ & White mass extruded \\
\hline $9: 45$ & $\cdots \ldots \ldots \ldots \ldots$ & Mass consumed by young \\
\hline
\end{tabular}

the posterior part of her body (that portion bearing the last 5 pairs of legs) raised at an angle of about $60^{\circ}$. She made no movements and no contraction or peristaltic action could be seen. The young on the other hand made active efforts to free itself and apparently maintained a constant tension. The portion of its body which had just emerged $(6 \mathrm{~mm})$ was very pale, almost white, and was separated from the rest of the body by a dark band $(2 \mathrm{~mm})$. These bands presumably represented extended and contracted regions respectively. The young was closely followed by a drop of white, cloudy, viscous liquid 1.5 to $2.0 \mathrm{~mm}$ in diameter. Manton (loc. cit.) states that in Peripatoides the cast egg membrane, the peritrophic membrane and the cast integument are evacuated after birth but no structure could be seen in this material. The mass was completely eaten by the young in half an hour. After parturition the mother showed no interest in the young even casually walking over it. However, neither did she attempt to harm or consume the young, either at this time or on succeeding days although she had been without food for the better part of a month.

With a length of half that of the mother the young appear large but their combined weight was less than 15 per cent of hers. In contrast to the adult which was uniformly colored a rich red-brown, the young showed a lighter red-violet-brown with pinker head, legs and underside. This difference in color appears to be characteristic in peripatus. 
An unsuccessful parturition was observed in a smaller individual of another species. ${ }^{7}$ Here the young was apparently injured and died when only one fourth extruded. In this case strong contractions of the posterior portion of the female's body were observed but she was unable to complete parturition more

TABLE 2

\begin{tabular}{lcccc}
\hline & \multirow{2}{*}{$\begin{array}{c}\text { Pairs } \\
\text { of legs }\end{array}$} & Weight & \multicolumn{2}{c}{ LENGTH IN MM. } \\
\cline { 4 - 5 } \cline { 4 - 5 } & in mg. & Contracted & Extended \\
\hline Adult & 33 & 786 & 50 & 60 \\
Young \#1 & 33 & 48 & 23 & 33 \\
Young \#2 & 34 & 54 & 24 & 31 \\
\hline \hline
\end{tabular}

than half way. Forceps delivery was resorted to in an attempt to save the adult, but unsuccessfully since she died about 12 hours later. It may well be that this failure was occasioned by placing the animal under observation since the smaller species was characteristically much more active and upset when removed from shelter. The larger species was much more tolerant of observation and for this reason may be particularly suitable material for studies on this group.

${ }^{7}$ This animal, also from Barro Colorado Island, was one of several Oroperipatus corradi. It had a contracted length of $36 \mathrm{~mm}$ and was a light chocolate color with a lighter under side and with darker legs and a dark, median dorsal stripe $0.3 \mathrm{~mm}$ wide. 

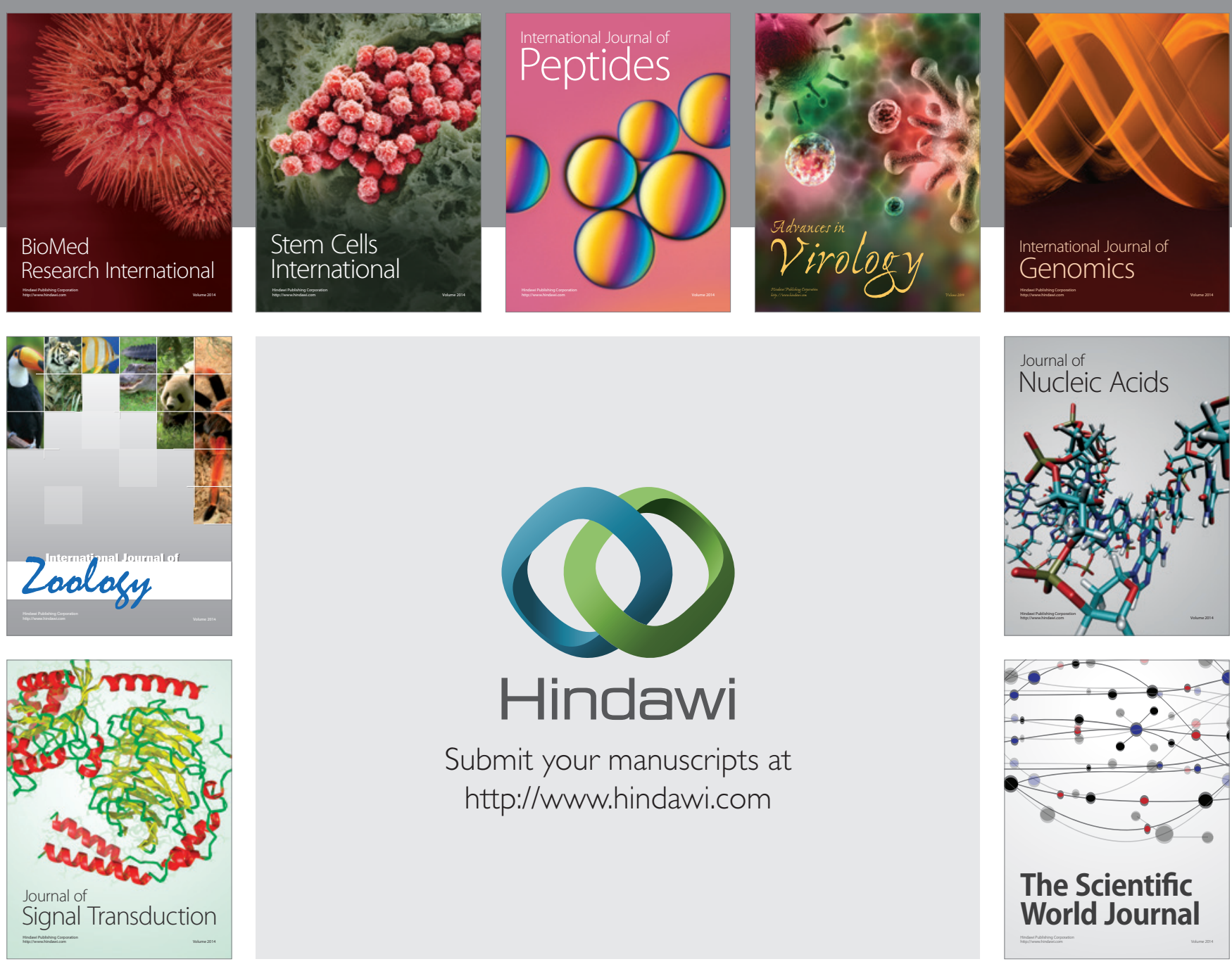

Submit your manuscripts at

http://www.hindawi.com
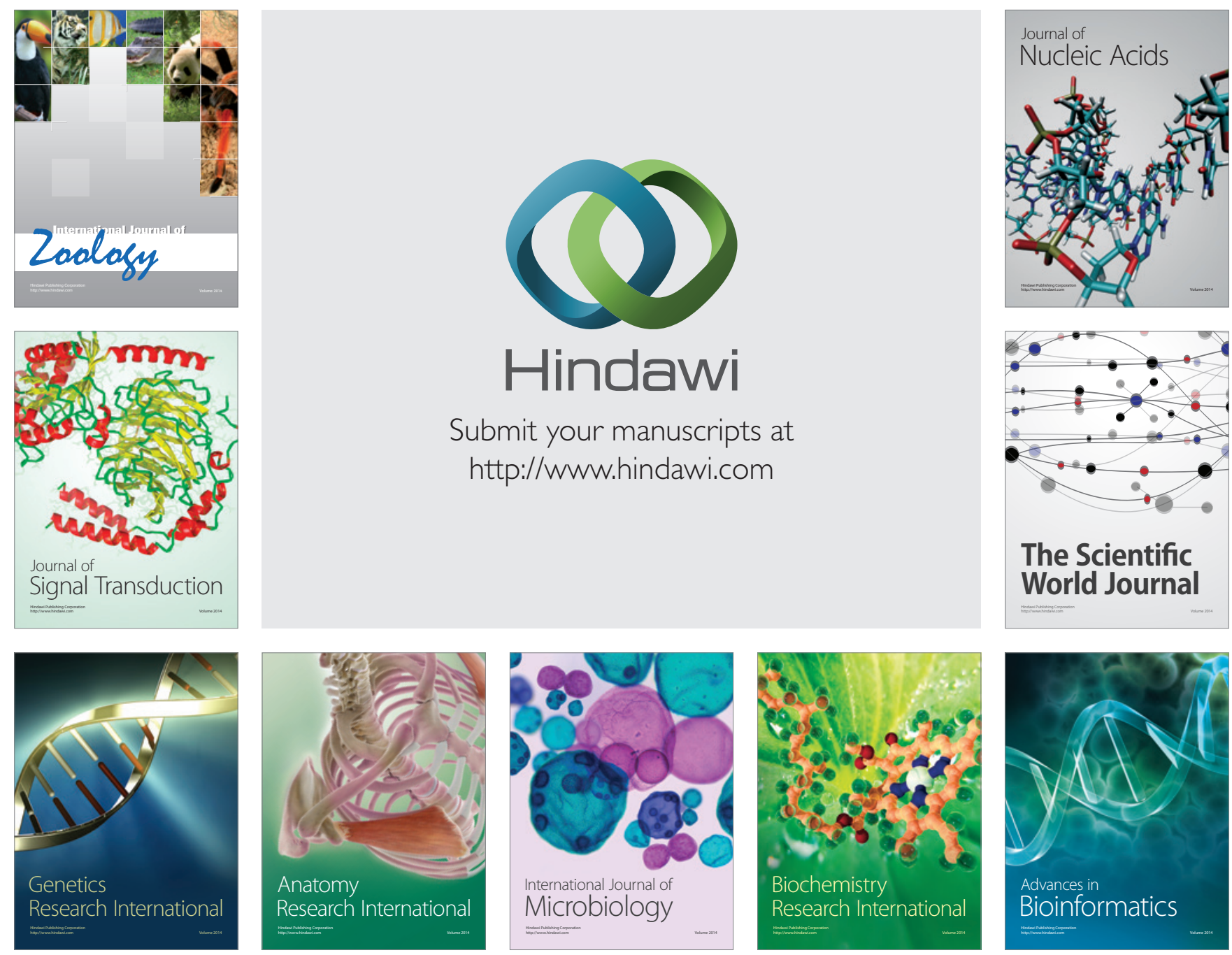

The Scientific World Journal
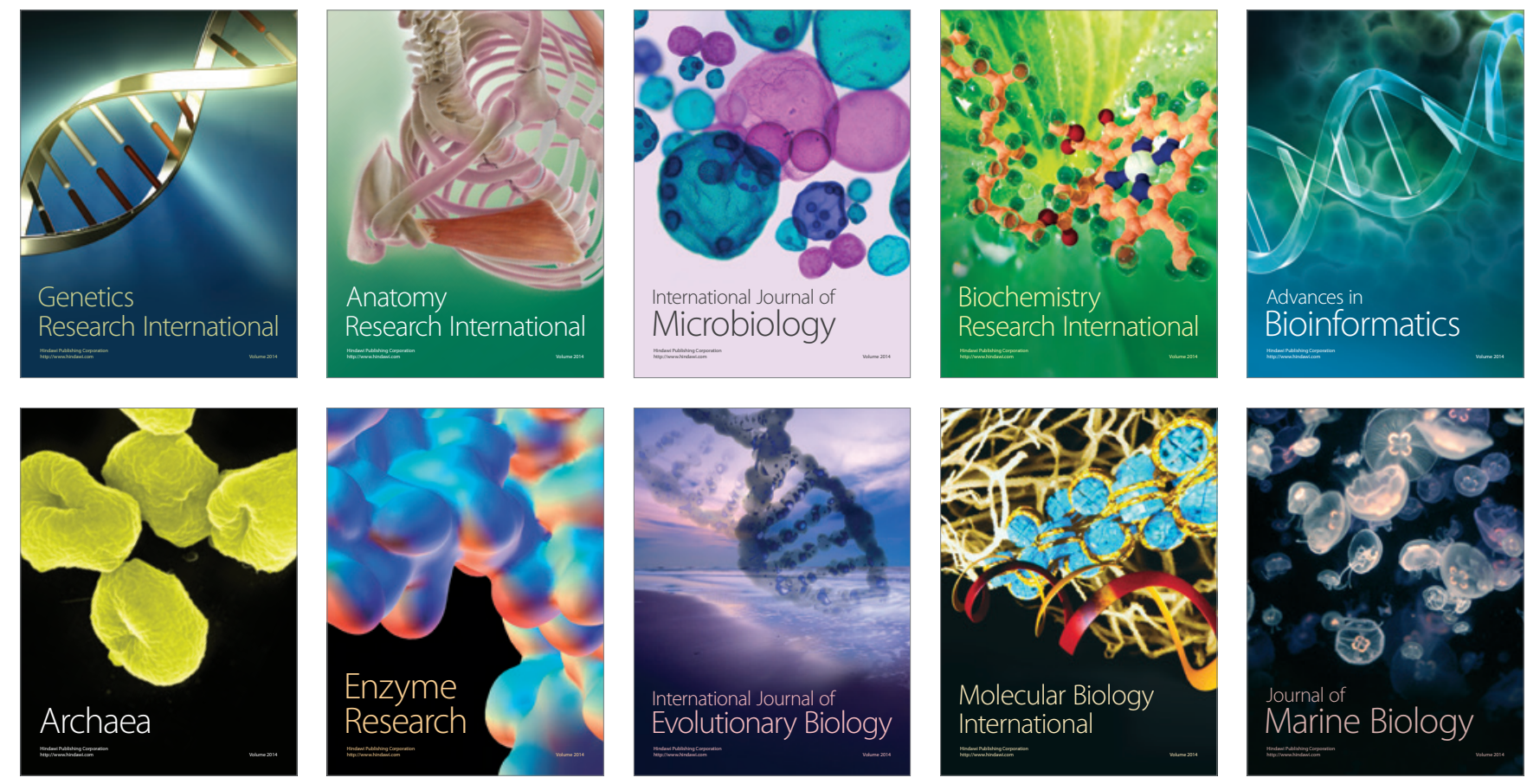